\title{
Problems of automation of fresh fruits and vegetables storage processes
}

https://doi.org/10.31713/MCIT.2020.34

\author{
Yevhenii Malanchuk \\ National University of Water and Environmental Engineering \\ Institute of Automatics, Cybernetics and Computer \\ Engineering \\ Rivne, Ukraine \\ e.z.malanchuk@nuwm.edu.ua
}

\author{
Andriy Khrystyuk \\ National University of Water and Environmental Engineering \\ Institute of Automatics, Cybernetics and Computer \\ Engineering \\ Rivne, Ukraine \\ a.o.khrystyuk@nuwm.edu.ua
}

\author{
Vladislav Sych \\ National University of Water and Environmental Engineering \\ Institute of Automatics, Cybernetics and Computer Engineering \\ Rivne, Ukraine \\ sych_ak15@nuwm.edu.ua
}

\begin{abstract}
The article contains materials for the analysis of control systems for the process of providing conditions for storage of fresh fruits and vegetables. The analysis reveals the shortcomings of existing management systems and outlines ways for further development.
\end{abstract}

Keywords-automation; storage processes; control system; automatic regulators

\section{INTRODUCTION}

Continuous supply of fresh fruits and vegetables to the population is possible only if they are stored properly for a long period after harvesting. But the storage of grown fruits and vegetables is hampered by the imperfection and low efficiency of existing technologies and means of preservation, as well as the lack of the necessary capacity of storage of succulent vegetable raw materials. The required volume of storage of plant products in Ukraine in accordance with existing regulations is 4916000 tons, including vegetables - 211200 tons, fruits 623000 tons. Existing storage facilities for vegetables and fruits account for $78.7 \%$ and $47.4 \%$, respectively. Storage capacity with artificial cooling is $15 \%$ of total demand. There are no refrigerated storages of small capacity (up to 500 tons) for storage of fruit products at the place of production (in the conditions of farms with different forms of ownership).

Losses of fruit and vegetable products during storage without the use of artificial cold are for: cabbage - 35-60\% ; carrots - 30$40 \%$; fruits and berries $-25-30 \%$; grapes $-15-25 \%$.

The imperfection of the storage of succulent plant products leads not only to its losses, but also to unproductive energy consumption and inefficient land use. And for refrigerated storage of lost products it would be necessary to spend only up to $4 \%$ of energy from the total amount of previous costs.
Therefore, one of the main tasks of the storage of fruits and vegetables is to improve existing and develop advanced technologies for long-term storage, fundamentally new cooling systems, energy-efficient modes of technological microclimate in storage, automated control of optimal modes using a computer.

Modernization of the storage industry requires a large number of refrigeration equipment, which requires the creation of technological measures for their energy efficiency, based on the development and implementation of energy-saving modes of air conditioning technological microclimate in storage facilities for fruit and vegetables based on machine cooling, automated control and cooling modes storage. Even insignificant energy savings (up to 5\%) while reducing losses per refrigeration unit in the total volume of fruit and vegetable production makes it possible to significantly reduce the energy load on the agricultural sector in Ukraine [1].

The peculiarity of fruits and vegetables as an object of storage are physiological-biological and other processes that continue in them in the postharvest period and are accompanied by heat release, the intensity and direction of which depends on the conditions of cooling and storage [2-3].

The release of heat of respiration puts the intensity of physiological processes in significant dependence on storage conditions (parameters of the microclimate in storage refrigeration chambers) [4].

Thus, for the implementation of energy and technologically efficient modes of operation of promising air cooling systems for fruit and vegetable storages, it is necessary to improve the control systems for temperature and humidity modes of cooling and storage of fruit and vegetable products. 


\section{Modeling, control and information technologies -2020}

Conditioning of microclimate of storage chambers is applied to maintenance of the set parameters of air in the storage chamber, i.e. its conditioning, is carried out by removal of heat and moisture emissions by ventilating air - the air processed in the conditioner which transits through the room and assimilates heat and moisture release in it. The drying capacity of ventilation air increases significantly with the assimilation of apparent (not related to moisture exchange) heat [1]. In addition, when moisture condensation (frost formation), the moisture content of the air decreases [5].

Therefore, in addition to the air temperature in the storage and cooling chambers, it is necessary to maintain the optimal humidity provided by the air conditioning system. To reduce shrinkage and compensate for dehydration of air from freezing during frost formation on the surface of the air cooler, it is necessary to increase the humidity of the air supplied to the chamber. The use of air conditioning systems allows to reduce the shrinkage of plant products by $20-30 \%$, which provides a certain economic effect.

Today on refrigerators for storage of fruit apply devices for artificial humidification of air and automatic regulation of relative humidity of air, according to biological features and stages of refrigerated storage of fruit.

\section{ANALYSIS OF LATEST RESEARCHES AND PUBLICATIONS}

The efficiency of storage equipment, which is determined by the degree of preservation of products and specific energy consumption to ensure rational modes, largely depends on the quality of its control system for temperature and humidity [13]. But today the systems of automatic control of refrigeration chambers of small capacity storage up to 500 tons are mainly built on the basis of thermostats. Such systems are simple and reliable, but have all the disadvantages of relay systems.

The adjustment is carried out by switching the compressor and fan drive on and off. This leads to significant temperature fluctuations in the chamber. It is known that product losses are greater in the presence of temperature fluctuations than simply when the temperature rises.

In cooling systems of holds with production temperature stabilization by change of a surface of a cooler and speed of giving of the fan is applied, and temperature of boiling of refrigerant is supported by the separate regulator of productivity of the screw compressor.

In a more advanced control system, the boiling point of the refrigerant and, accordingly, the temperature in the chamber is carried out by changing the performance of the compressor in such a way that simultaneously with the adjustment to the optimal temperature pressure, which determines the energy loss of the cycle.

The technical implementation of the optimal control law is carried out in the class of relay structures with an infinitely large gain, using relay elements operating in sliding mode, which allowed to obtain high accuracy of approximation of the selected control law.
The high inertia of the potato embankment and the peculiarities of the design of the potato storage in the form of the same type of bins have determined the feasibility of creating a multi-channel automatic control system with sequential survey, formation and publication of regulatory effects. The control system includes a survey unit, control and analysis device, logic device, control devices, temperature and humidity sensors, actuators.

One of the features of automation systems for air conditioning in storage chambers is the need to restructure the air treatment scheme when changing the heat-moisture ratio, which is carried out by switching on the operation of a technological process. For this purpose the knot of automatic transition from one regulating body to another at smooth regulation of the controlled variable with correction of parameters of adjustment of regulation system is developed. [6] The proposed control scheme fully provides the desired dynamic properties of the automatic control system for both control effects.

Automatic regulators used in air conditioning systems in refrigerated storage chambers are designed mainly to provide regulatory values of indoor air parameters. However, to increase the economic efficiency of air conditioning systems, for example, on the basis of the methods of A. Ya. Kreslin and A.A Rymkevich [7], it is necessary to maintain optimal energy consumption parameters within the normative values. In this case, the requirements for the accuracy of stabilization of temperature and humidity are significantly increased.

The solution of these problems is difficult due to the lack of appropriate industrial regulators. Their nomenclature for control systems allows to implement only simple local systems of automatic control; to create with their help the lower level of control of the automated control system of technological process at the decision of optimization problems it is practically impossible.

Autonomous interdependent control systems are used to create high-precision control schemes for temperature and humidity regimes of agricultural automation facilities. The essence of the idea of autonomous control is that by introducing corrections that compensate for the relationships between regulators, achieve the decomposition of a complex system with interdependent parameters into a number of simplest separative systems with one adjustable value. At the same time achieve full compensation of internal connections between adjustable parameters, providing selective invariance with respect to perturbations propagating through cross channels.

In the practice of agricultural production in the regulation of temperature and humidity regimes of agricultural objects of automation the most widespread are autonomous systems with direct compensating connections.

The structural analysis of the automatic control system carried out in [8] allows to determine that for the considered class of agricultural objects of automation, which are based on the functioning of heat and mass transfer processes, it is rational to use the unrelated control principle. Unconnected control systems are known to be cheaper and more reliable than the 


\section{Modeling, control and information technologies $\mathbf{- 2 0 2 0}$}

corresponding multidimensional control systems, which is especially important for agricultural production conditions, where the issues of reliability and stability of control systems are of particular importance.

In the automatic system of regulation of air parameters in air conditioners the general industrial $\mathrm{P}-$, PI- and PDregulators, which implement the standard $\mathrm{P}-$, PI- and PDcontrol laws, respectively, are traditionally used. When designing such automatic control systems do not always take into account the dynamic properties of the object, which reduces the quality of regulation.

In order to develop an automated control system for the enthalpy of air at the outlet of the heat exchanger, which takes into account the static and dynamic properties of the equipment of the ship's air conditioner in [4], the choice of control law is justified. For this purpose, the root mean square error of regulation when using these regulators is determined. The results of calculations performed in [2] showed that for $\mathrm{P}-$, PIand $\mathrm{PD}$ - regulators it is equal to $392.95 * 10^{-3}, 5.309 * 10^{-3}$ and $164.223 * 10^{-3} \mathrm{~kJ} / \mathrm{kg}$, respectively. Given the presence of fluctuations in the controlled parameters when introducing the integrating component in the P-control law, as well as the deterioration of the dynamic properties due to the possible loss of stability, the use of PI-regulator is undesirable. In the case of the application of the PD-regulator, the introduction of the derivative into the P-law of control significantly improves the quality indicators, but complicates the control scheme. In connection with the above, it is best to use a system with $\mathrm{P}$ control law, if the presence of static error is allowed.

As researches have shown, at regulation of a microclimate on deviations of enthalpy of application of PI, PD of regulators it is inexpedient, thus loss of stability is possible. $\mathrm{n}$ this regard, a combined automatic control system was developed, which provides compensation for the effect of changes in the enthalpy of air in front of the heat exchanger on the enthalpy of air at its outlet. As a result of researches of the combined automated system of regulation of enthalpy of air at a heater exit the optimum value of the adjusted parameter $\mathrm{q}=12.51 \mathrm{~kJ} / \mathrm{kg}$ (specific energy consumption) is defined. It is established that in the combined ACP with a $100 \%$ increase in the enthalpy of air at the inlet to the heat exchanger, the maximum dynamic deviation is $13 \mathrm{~kJ} / \mathrm{kg}$, which is 1.31 times less than in a singlecircuit ACP. The static control error in the steady state is zero.

Thus, existing relay and PI regulators may not always compensate for disturbances in conditions of uncertainty, which are due to a sharp change in environmental parameters, both daily and seasonal with periodic variable load.

It is known that the change of atmospheric air parameters in the seasonal periods "autumn-winter-spring" causes significant nonstationarity and nonlinearity of a number of characteristics of technological equipment of fruit and vegetable storages as a result of the problem of choosing the law of regulation and parameters of regulators.

Structural and thermophysical parameters of refrigerated storage chambers of plant products are constantly perturbed (changes in mass and volume of products during loading, heat exchange surface area and other indicators), which leads to uncertainty. It is quite natural that even the most effective PI law of regulation cannot compensate for perturbations in conditions of uncertainty. Therefore, when using modern approaches to maximize the creation of an optimal control system when formulating a decision that to form the current value of power change by the criterion of temperature stabilization in the chamber, it is advisable to deviate from traditional control methods and move to intelligent methods that will flexibly adapt to changing internal parameters. object and perturbations in a wide range of changes in their values.

The use of a linguistic approach to the management of microclimate parameters and heating is already being used. In [9-10] the high efficiency of the fuzzy system of automatic control of the heater and air conditioner was proved

In [11] it was shown that the use of a room temperature control system with a fuzzy controller in conditions of nonstationary perturbations allows to stabilize the temperature regime, while a system with a PI controller has an autooscillating transition process.

There are positive attempts to use microclimate control systems with fuzzy logic [6]. The system measures the air temperature in the room and automatically selects the operating mode and the required refrigeration capacity of the compressor, and the set air temperature is constantly adjusted based on the current values of temperature and humidity in the room. Compared with PID control, air temperature fluctuations are significantly reduced $[9,10]$.

The use of fuzzy logic controllers in controlling the microclimate system ensures: no sudden temperature changes in the room, maintaining the allowable air flow rate, setting the required cooling capacity, selecting the operating mode for temperature and humidity in the storage, minimum time to enter a given mode, reducing energy consumption $20-40 \%$.

Thus, the analysis of the reasons of low efficiency of functioning of regulated systems of refrigerated supply of storage chambers of fruit and vegetable storages (refrigeration units) allows to define the basic directions of improvement of process of management of operating modes of refrigerating appliances for maintenance of regulated temperature and humidity modes:

- transition from positional to continuous algorithms of refrigeration unit control;

- use to control the parameter of the object that most informatively characterizes the heat load and can be measured automatically;

- transition from the traditional system of automatic regulation of the parameters of the technological microclimate of storage facilities, to object management systems based on the use of fuzzy logic (which reduces energy consumption by $20 \%)$

- use to describe the dynamics of functionally complete complex models created by the deterministic principle and identified according to field experiments; 


\section{Modeling, control and information technologies -2020}

- construction of productive models of energy consumption on the basis of fuzzy neural networks.

\section{CONCLUSIONS}

Among the variety of created mathematical models that allow to determine the transfer functions of control objects and correctly synthesize systems for automatic control of temperature and humidity regimes of fruit and vegetable storages are only those that reproduce the dynamics of certain elements of the system. Models that reflect the complex of all elements and the relationship between them, still need to be developed.

To quantify the effectiveness of ways to improve the functioning of the technological process of storage, it is first necessary to identify the control parameters that most fully characterize the state of the object at a given time and can be directly measured, as well as control and disturbing effects.

In most cases, the systems of automatic control of parameters in refrigerators are developed without taking into account the mutual influences of technological parameters, insufficiently substantiated structures and laws of regulation of individual elements of equipment, as well as the location of temperature and humidity sensors. The use as a parameter of the regulated "average" air temperature when the sensor is installed in the geometric center of the chamber leads to significant temperature fluctuations $\left( \pm 2.5 \ldots 3^{\circ} \mathrm{C}\right)$, which leads to increased product losses. In the general case, the issue of regulating the microclimate of storage facilities has not yet been fully resolved.

Practical operation of refrigeration units of fruit and vegetable storages occurs at the incomplete information on a condition of object of management that complicates application of classical methods of optimum management. However, in connection with the development of methods of fuzzy set theory and fuzzy logic, it is possible to organize another approach to the synthesis of automation control system for temperature and humidity modes of refrigeration systems, which is to use fuzzy logic to solve the scientific problem of refrigeration control. fruit and vegetable products in the face of partial uncertainty of this process and established intelligent control systems. The peculiarity of such systems is that the model and the mechanism of logical inference are separate parts, which makes it possible to improve the model or change it without changing the inference.

\section{REFERENCES}

[1] Bedin F. N. Tekhnologiya khraneniya rastitel'nogo syr'ya. Fiziologicheskiye, teplofizicheskiye i transportnyye svoystva: / F. P. Bedin, Ye. F. Balan, N. I. Chumak. - O.: Astroprint, 2002. - 306 p.

[2] Chumak I. G. Dinamicheskiye rezhimy raboty kholodil'nykh ustanovok i apparatov / I. G. Chumak, A. I. Kokhanskiy. - M.: Mashinostroyeniye, 1978. $-192 \mathrm{p}$

[3] Practical Heating Technology, 2nd Edition Bill Johnson, Kevin Standiford, William Johnson. NK: Delmar, CENGAGE Learning, 2009. $-515 \mathrm{p}$.

[4] Herrera F. Tackling real-coded genetic algorithms: operators and tools for the behavior analysis / F. Herrera, M. Lozano, J. Verdegay // Artificial Intelligence Review. - 1998. - Vol. 12. - № 4. - pp. 265-319.

[5] Lakhmi C. J. Fusion of Neural Networks, Fuzzy Systems and Genetic Algorithms: Industrial Applications / Lakhmi C. Jain, N. M. Martin. Boca Raton, FL: CRC Press, 1998. - 368 p.

[6] Bondar YU. S. Peredovi tekhnolohiyi v keruvanni kondytsioneramy / Kholod. - 2004. - № 4. - pp. 38-39

[7] Rymkevich A. A. Upravleniye sistemami konditsionirovaniya vozdukha / Rymkevich A. A., Khalameyzer M. B. - M.: Mashinostroyeniye, 1977. -274 p.

[8] Martynenko I. I. Avtomatizatsiya upravleniya temperaturnovlazhnostnymi rezhimami sel'skokhozyaystvennykh ob"yektov /Martynenko I. I., Girnyk N. L., Polishchuk V. M. - M.: Kolos, 1984. $152 \mathrm{p}$.

[9] Mikhaylenko V. S. Analiz metodov razrabotki nechetkikh SAR dlya upravleniya slozhnymi vzaimosvyazannymi ob"yektami / V. S. Mikhaylenko, V. F. Lozhechnikov // Avtomatika. Avtomatizatsiya. Elektrotekhnicheskiye kompleksy i sistemy. - 2009. - № 1. - pp. 171176.

[10] Mikhaylenko V. S. Metody nastroyki nechetkogo adaptivnogo PIDregulyatora / V. S. Mikhaylenko, V. F. Lozhechnikov // Avtomatika. Avtomatizatsiya. Elektrotekhnicheskiye kompleksy i sistemy. - 2009. № 2. - pp 174-179.

[11] Mikhaylenko V. S. Nechetkaya avtomaticheskaya sistema upravleniya vozdushnym otopleniyem vystavochnogo tsentra / V. S. Mikhaylenko, A. N. Kharabet // Kholodil'na tekhníka í tekhnologíya. - 2007. - № 5. pp. $72-76$. 